\title{
Papillary craniopharyngioma in a patient following resection of nonfunctioning pituitary adenoma: illustrative case
}

\author{
David J. Park, MD, PhD, ${ }^{1,2}$ Akash Mishra, ${ }^{1,2}$ Danielle Golub, MD, ${ }^{1,2}$ Jian Y. Li, MD, PhD, ${ }^{1,3}$ Karen S. Black, MD, ${ }^{1,4}$ and Michael Schulder, MD ${ }^{1,2}$ \\ 'Zucker School of Medicine at Hofstra/Northwell, Hempstead, New York; and Departments of ${ }^{2}$ Neurosurgery, ${ }^{3}$ Radiology, and ${ }^{4}$ Pathology and Laboratory Medicine, North Shore \\ University Hospital, Manhasset, New York
}

\begin{abstract}
BACKGROUND Although craniopharyngioma and pituitary adenoma are common tumors of the sellar or suprasellar region, the development of papillary craniopharyngioma in the same sellar region after resection of a nonfunctioning pituitary adenoma has not been reported.

OBSERVATIONS Here the authors report the first case of craniopharyngioma that developed long after resection of a pituitary adenoma. A 66-yearold male patient underwent endoscopic transsphenoidal resection for a large sellar mass, which histopathologically confirmed the diagnosis of a pituitary adenoma. He had an excellent recovery after surgery. For several years, he had no clinical or imaging evidence of tumor recurrence and then was lost to follow-up. Seven years after the initial surgery, the patient returned with a one-month history of visual field defects, and imaging confirmed a heterogeneous, cystic suprasellar mass. Endoscopic transsphenoidal resection of the tumor was performed, and histological examination showed it to be a papillary craniopharyngioma.
\end{abstract}

LESSONS Neurosurgeons should be aware that after pituitary adenoma resection, a recurrent mass could be a craniopharyngioma, with implications for very different management recommendations.

https://thejns.org/doi/abs/10.3171/CASE2063

KEYWORDS craniopharyngioma; pituitary adenoma; transsphenoidal surgery; papillary type craniopharyngioma; sellar; suprasellar

Pituitary adenomas (PAs) and craniopharyngiomas (CPs) are tumors of the sellar or suprasellar region. PAs account for $10 \%-15 \%$ of all intracranial tumors, with an annual incidence of 0.2 to 2.8 cases per 100,000 persons. ${ }^{1}$ These neoplasms originate from the anterior lobe of the pituitary gland. ${ }^{2}$ Although PAs may induce hypersecretory symptoms, a large portion (14.7\%-39\%) are nonfunctioning and do not produce excessive hormones. ${ }^{3}$ Nonfunctioning PAs (NPAs) originate from adenohypophyseal cells and are not associated with clinical evidence of hormonal hypersecretion. ${ }^{4}$ These tumors are often found incidentally on imaging studies acquired because of unrelated symptoms. The absence of clinical manifestations of hormonal hypersecretion is the reason that NPAs are frequently diagnosed when they are large enough to cause mass effect on surrounding structures, ${ }^{4}$ causing symptoms such as headaches, visual disturbances, or cranial nerve dysfunction. Other manifestations are hyperprolactinemia due to pituitary stalk deviation, and, less frequently, pituitary apoplexy. ${ }^{5}$ The first line of treatment for symptomatic or enlarging NPA is transsphenoidal resection; tumor regrowth is often treated with radiation therapy or stereotactic radiosurgery and is assessed periodically via neuroimaging. ${ }^{6}$

CPs are much rarer than PAs, composing $1 \%$ to $4 \%$ of all intracranial tumors. ${ }^{7}$ They originate from ectodermal remnants of Rathke's pouch between the adenohypophysis and neurohypophysis in the region of the pars tuberalis. ${ }^{8}$ There are two different subtypes of CPs that differ clinically and pathologically: the adamantinomatous $\mathrm{CP}$ (ACP) and papillary CP (PCP) types. They have a bimodal distribution, with peak incidence in children at $5-15$ years of age and adults with an age $>40$ years. The ACP occurs predominantly in the pediatric population, whereas the PCP is seen mostly in adults. The ACPs are much more common than PCPs $(9: 1)$ and are pathologically distinct. ${ }^{9}$ ACPs arise from remnants of the embryonic craniopharyngeal duct, which connects Rathke's pouch to the stomodeum during development. They can be solid or form a cystic structure filled with dark brown to black fluid and are frequently calcified. PCPs are thought to result from metaplasia

ABBREVIATIONS $\mathrm{ACP}=$ adamantinomatous craniopharyngioma; $\mathrm{CP}=$ craniopharyngioma; $\mathrm{MRI}=$ magnetic resonance imaging; $\mathrm{NPA}=$ nonfunctioning pituitary adenoma; $P A=$ pituitary adenoma; $P C P=$ papillary craniopharyngioma.

INCLUDE WHEN CITING Published January 11, 2021; DOI: 10.3171/CASE2063.

SUBMITTED October 12, 2020. ACCEPTED October 15, 2020.

(C) 2021 The authors, CC BY-NC-ND 4.0 (http://creativecommons.org/licenses/by-nc-nd/4.0/), 

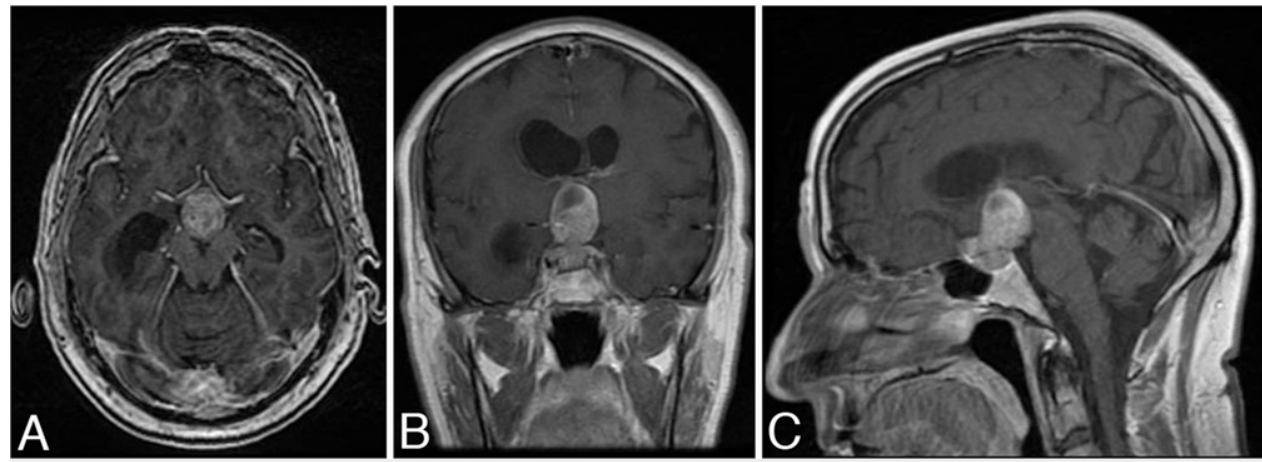

FIG. 1. Initial preoperative MRI. Axial (A), coronal (B), and sagittal (C) contrast-enhanced T1-weighted images. A $3.8 \times 2.1 \times 2.4-\mathrm{cm}$, heterogeneously enhancing sellar and suprasellar mass is visible, most suggestive of a pituitary macroadenoma. The tumor contains hemorrhage and necrosis within the suprasellar component, and it has slight extension into the right cavernous sinus.

of the adenohypophysial cells in the pars tuberalis. ${ }^{10}$ They are usually well-circumscribed and can also be solid or cystic and filled with yellow and viscous fluid. In contrast to ACPs, PCPs are usually not calcified. Patients with a CP typically present with a wide range of symptoms, similar to PA. The first-line treatment for patients with these tumors is resection, but because of their location in proximity to vital neurovascular structures, often only partial resection is possible. Several surgical approaches have been developed depending on the topographical location of the tumor; postoperative radiotherapy, Gamma Knife radiosurgery, and the occasional use of Ommaya reservoir placement, proton beam therapy, and intracavitary $\beta$-irradiation has been reported in the literature. ${ }^{11}$

NPAs and CPs share a similar intracranial location; however, the coexistence of these tumors is extremely rare. To the best of our knowledge, since 1971, there have been only 17 cases of synchronous collision tumors, rare clinical entities wherein two histologically distinct tumor types occur at the same anatomical location simultaneously or within 6 months of one another. ${ }^{12-28}$ Metachronous collision of NPAs and CPs being diagnosed at least 6 months apart have been reported only twice in the previous literature, with a $\mathrm{CP}$ arising in a patient after surgery for a functioning PA.29,30 To our knowledge, this is the first reported case of a PCP developing in a patient after resection of an NPA.

\section{Illustrative Case}

A 66-year-old male patient came to the emergency department displaying confusion and imbalance. He had a bitemporal hemianopsia on examination. Endocrine laboratory tests showed no apparent hormonal disturbances. His initial brain computed tomography scan showed a $2.1 \times 1.9-\mathrm{cm}$ heterogeneous mass in the sellar and suprasellar region that was exerting a mass effect upon the anterior third ventricle and causing obstructive hydrocephalus. Magnetic resonance imaging (MRI) showed a $3.8 \times 2.1 \times 2.4-\mathrm{cm}$, heterogeneously enhancing mass consistent with a pituitary macroadenoma (Fig. 1). The tumor contained hemorrhage and necrosis within the suprasellar component, and it had slight extension into the right cavernous sinus. Having the impression that the tumor was a pituitary macroadenoma, we completely removed it through an endoscopic transsphenoidal resection (Fig. 2). A vascularized nasoseptal flap and an abdominal fat graft were used to prevent postoperative cerebrospinal fluid leakage. Histopathological examination confirmed the diagnosis of an NPA (Fig. 3A). Immunohistochemical stains showed PA cells that were patchily positive for adrenocorticotropic hormone, whereas they were negative for prolactin, growth hormone, thyroid-stimulating hormone, luteinizing hormone, and follicle-stimulating hormone. The patient had an excellent recovery with normalization of his vision and mental status,
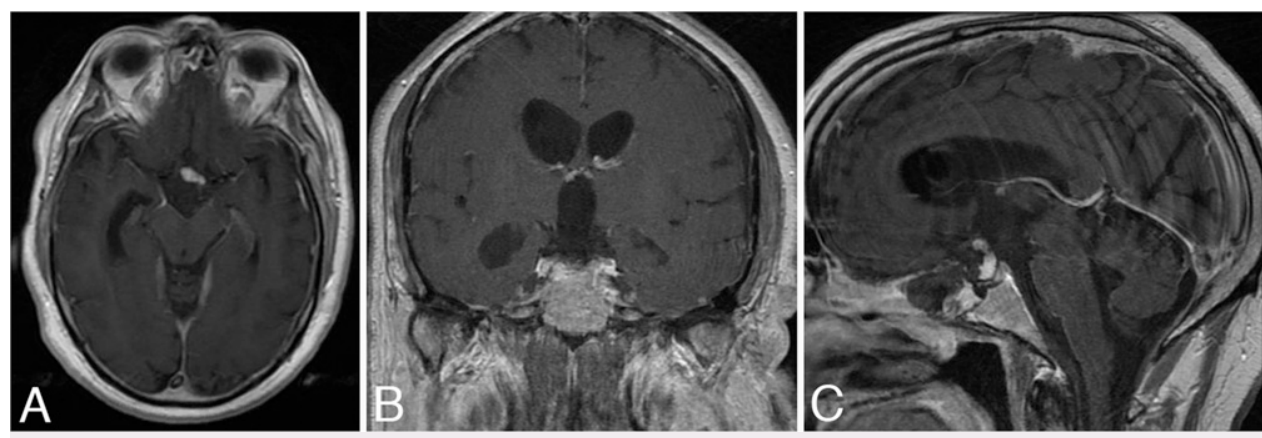

FIG. 2. Postoperative MRI after initial surgery. Axial (A), coronal (B), and sagittal (C) contrast-enhanced T1weighted images. Gross-total resection of the tumor was done. Ventricular size normalized on follow-up imaging. 

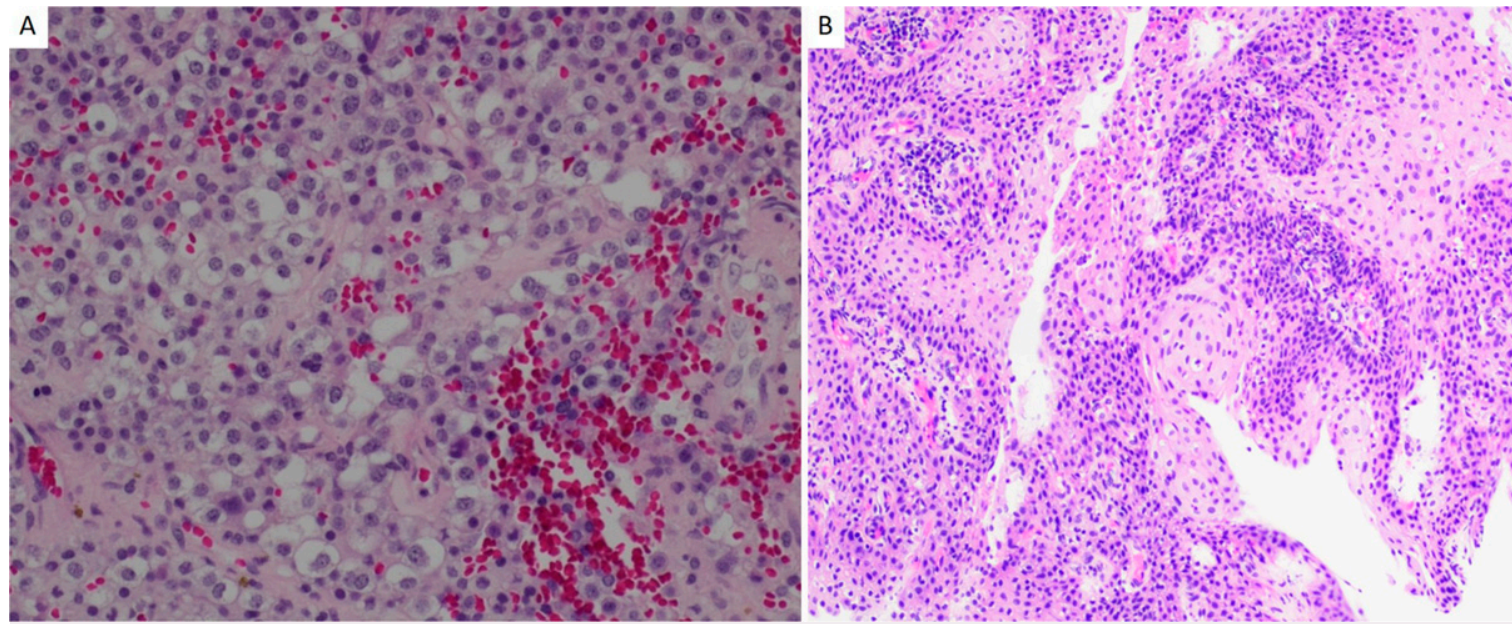

FIG. 3. Histopathological comparison of each tumor specimen. A: Hematoxylin and eosin stain shows a PA with intratumor hemorrhage (original magnification $\times 400$ ). B: Hematoxylin and eosin stain demonstrates a PCP (original magnification $\times 100$ ).

although the hypopituitarism remained and was corrected with medication. He was followed up for four years, including serial MRI, but stopped coming for routine examinations after that point.

Seven years after surgery, or 3 years after the last follow-up, the patient came back complaining of blurred vision. He had decreased visual acuity in the right eye and a bitemporal hemianopsia. Also, the MRI showed a $2.3 \times 2 \times 1.9-\mathrm{cm}$ heterogeneous cystic mass at the sellar region, compressing the optic chiasm and involving the cavernous sinus (Fig. 4). Ventricles were also enlarged compared to the previous scan. The presumed diagnosis was a recurrent and largely cystic NPA. Given the patient's age and frail appearance, as well as the ongoing coronavirus disease 2019 (COVID-19) pandemic, we sought to address his main symptom of visual loss by placing a catheter into the cyst, draining the cyst, and attaching the catheter to an Ommaya reservoir. This was unsuccessful in that the catheter appeared to curve around the cyst capsule (Fig. 5). After surgery, the patient's mental status declined despite adequate hormonal replacement. To address his visual loss, endoscopic transsphenoidal resection of the tumor was performed with opening of the cyst, visualization of the third ventricle, and removal of the solid tumor. This tumor proved to be a PCP with a BRAF V600E mutation (Fig. 3B).

The patient ultimately required placement of a ventriculoperitoneal shunt, at another institution as per the family's request, with an excellent recovery of his mental status. Given the presence of a BRAF V600E mutation in this tumor, treatment with a BRAF inhibitor will most likely be the treatment of choice if and when tumor recurrence is observed.

\section{Discussion \\ Observations}

To our knowledge, this is the first reported case of a PCP developing in a patient with a resected NPA years after the initial surgery. The metachronous coexistence of these two histologically distinct tumors within one individual is unique.

Collision lesions of the sellar region of CPs and PAs have been described in a total of 17 cases, but there has only been one report of a patient presenting with both a PCP and an NPA synchronously. In that
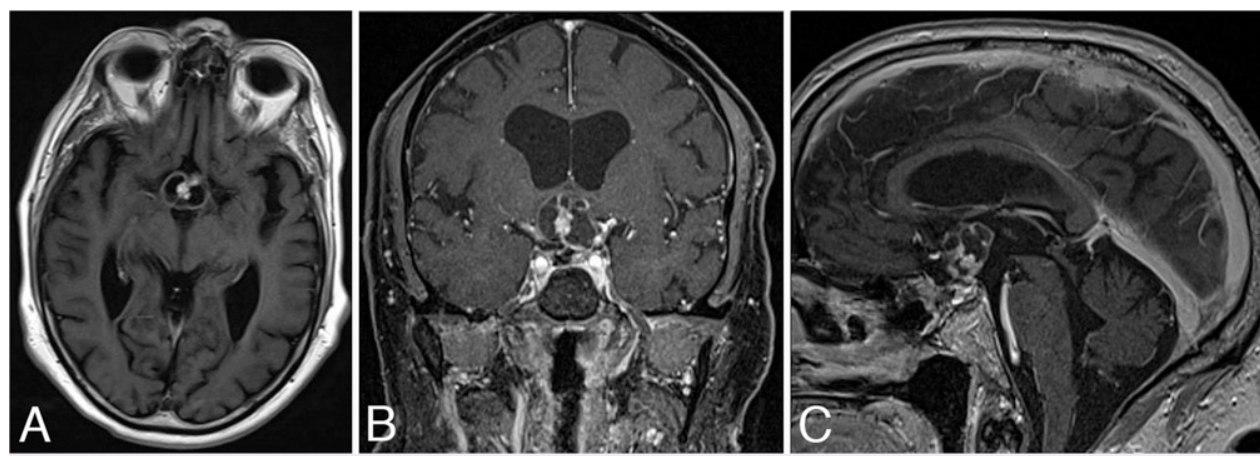

FIG. 4. MRI seven years after surgery. Axial (A), coronal (B), and sagittal (C) contrast-enhanced T1-weighted images. A $2.3 \times 2 \times 1.9-\mathrm{cm}$ complex mass with cystic and solid components is noted at the sellar region, compressing the optic chiasm and involving the cavernous sinus. In retrospect, the imaging features of this cystic lesion are consistent with a CP. 

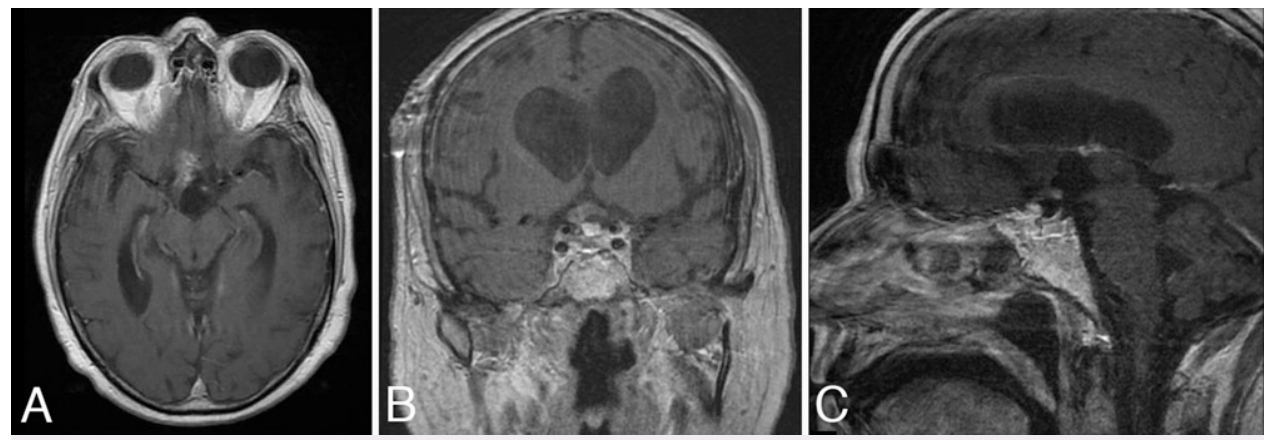

FIG. 5. Postoperative MRI. Axial (A), coronal (B), and sagittal (C) contrast-enhanced T1-weighted images. Majority of the tumor was resected and there was minimal residual enhancement in the region of the chiasmatic cistern and anterior third ventricle.

case, the patient presented at a younger age ( 35 years). ${ }^{28}$ Furthermore, very few cases exist of any $C P$ presenting in a patient after resection of a PA. We found two reports of the metachronous presentation of a $\mathrm{CP}$ and a functioning PA (Table 1). ${ }^{29,30}$ Most notably, when examining the two other previously reported cases of NPA leading to PCP, we noted our current patient was significantly older. The three patients were each lost to follow-up prior to presentation with CP. In Guaraldi et al. ${ }^{30}$ as well as the current case, neuroimaging showed no significant growth of the PA at last follow-up two and three years prior to $\mathrm{CP}$ presentation, respectively; therefore, it can be inferred that aggressive $\mathrm{CP}$ growth occurred in the short time frame between the latest follow-up and representation.

Both PCPs and NPAs share a similar embryonic region, stemming from different regions of Rathke's pouch early in development. However, the pathogenesis remains unclear. These tumors may hypothetically derive from a single cell undergoing divergent differentiation or may derive from different stem cells that give rise to two different neoplasms. More than $70 \%$ of ACPs have a mutation of the beta-catenin gene, leading to accumulation of nuclear beta-catenin protein. The crucial pathogenetic event appears to be WNT/beta-catenin activation in ACP, whereas itappears to be activation of the Ras/Raf/MEKJERK pathway by the BRAF V600E mutation in PCP. ${ }^{31}$ It is still possible that there was a common genetic mutation serving as the cause of both tumors. A common genetic abnormality may be the key explanation for the formation of these two different tumors in the same individual. To this end, there has been one study proposing mutations in beta-catenin as a common source factor for the genesis of ACPs and PAs, but no such connection is known to exist between PCPs and PAs.
It is similarly possible that an environmental factor yielded a similar result. Predisposing factors, such as inflammation, trauma, and metaplastic change in PAs following irradiation, have been considered in some cases. ${ }^{28}$ In our case, the only possible environmental factor to be considered would be trauma or cautery from the initial surgery.

In retrospect, if the patient had continued his planned follow-up and been imaged earlier, he might have been treated with stereotactic radiosurgery or stereotactic radiotherapy on the assumption that he had a recurrent NPA. Cyst aspiration and catheter placement were attempted based on the same assumption, and the patient's age and the potential COVID-19-related risks of resection were additionally considered. In hindsight, moving sooner to transnasal resection would have made the diagnosis of CP occur sooner, although the patient would still have needed shunt placement based on his postoperative course. BRAF mutations have been reported in patients with CPs, with favorable responses to vemurafenib, dabrafenib, and MEK inhibitors. ${ }^{32-37}$ Of course, without a new biopsy showing a $\mathrm{CP}$, there would have been no basis for using any of these agents in our patient.

\section{Lessons}

We report the first case of a patient who developed a CP long after resection of an NPA. Patients diagnosed with an NPA should maintain careful follow-up, but if recurrence is seen after several years, a cystic appearance on MRI may indicate that the patient has a $\mathrm{CP}$. If so, rather than empirical irradiation, resection will be needed to relieve symptoms, confirm the diagnosis, and possibly point the way to medical therapy.

TABLE 1. Review of patient cases with metachronous presentation of CP after resection of PA

\begin{tabular}{lccccccc}
\hline \multicolumn{1}{c}{ Study } & & & & \multicolumn{3}{c}{ Histology (Types) } \\
\cline { 3 - 6 } & Gender & Age at PA Diagnosis (yrs) & Age at CP Diagnosis (yrs) & PA & CP & Length of Follow-Up (yrs) \\
\hline El-Bilbeisi et al. $2010^{29}$ & $\mathrm{~F}$ & 33 & 41 & GH & Not reported & 18 \\
\hline Guaraldi et al. $2013^{30}$ & $\mathrm{~F}$ & 27 & 38 & PRL & PCP & 2 \\
\hline Our case & $\mathrm{M}$ & 67 & 74 & NPA & PCP & 3 \\
\hline
\end{tabular}

$\mathrm{GH}=$ growth hormone-secreting $\mathrm{PA} ; \mathrm{PRL}=$ prolactinoma. 


\section{References}

1. Asa SL, Ezzat S. The cytogenesis and pathogenesis of pituitary adenomas. Endocr Rev. 1998;19(6):798-827.

2. de Divitiis E, Esposito F, Cavallo LM, etal. Pituitary adenomas and craniopharyngiomas. Clin Neurosurg. 2005;52:112-115.

3. Aflorei ED, Korbonits M. Epidemiology and etiopathogenesis of pituitary adenomas. J Neurooncol. 2014;117(3):379-394.

4. Fleseriu M, Karavitaki N. Non-functioning pituitary adenomas, not all the same and certainly not boring! Pituitary. 2018;21(2):109-110.

5. Chen L, White WL, Spetzler RF, et al. A prospective study of nonfunctioning pituitary adenomas: presentation, management, and clinical outcome. J Neurooncol. 2011;102(1):129-138.

6. Lucas JW, Bodach ME, Tumialan LM, et al. Congress of neurological surgeons systematic review and evidence-based guideline on primary management of patients with nonfunctioning pituitary adenomas. Neurosurgery. 2016;79(4):E533-E535.

7. Bunin GR, Surawicz TS, Witman PA, et al. The descriptive epidemiology of craniopharyngioma. J Neurosurg. 1998;89(4): 547-551.

8. Komotar RJ, Starke RM, Raper DM, et al. Endoscopic endonasal compared with microscopic transsphenoidal and open transcranial resection of craniopharyngiomas. World Neurosurg. 2012;77(2): 329-341.

9. Larkin SJ, Ansorge O. Pathology and pathogenesis of craniopharyngiomas. Pituitary. 2013;16(1):9-17.

10. Haston S, Pozzi S, Carreno G, et al. MAPK pathway control of stem cell proliferation and differentiation in the embryonic pituitary provides insights into the pathogenesis of papillary craniopharyngioma. Development. 2017;144(12):2141-2152.

11. Lubuulwa J, Lei T. Pathological and topographical classification of craniopharyngiomas: a literature review. J Neurol Surg Rep. 2016; 77(3):e121-e127.

12. Prabhakar V, Rao BD, Subramanyam MV. Pituitary adenoma associated with craniopharyngioma. J Pathol. 1971;103(3):185-187.

13. Shishkina VL, Kasumova S, Snigireva R, et al. [Craniopharyngioma associated with pituitary adenoma and chordoma of Blumenbach's clivus]. Article in Russian. Vopr Neirokhir. 1981;(6):52-54.

14. Wheatley T, Clark JD, Stewart S. Craniopharyngioma with hyperprolactinaemia due to a prolactinoma. J Neurol Neurosurg Psychiatry. 1986;49(11):1305-1307.

15. Dong Y, Song YX, Qi W. A case of pituitary adenoma associated with craniopharyngioma. Chinese Journal of Neurosurgery. 1986;2:195.

16. Asari J, Yamanobe K, Sasaki T, et al. A case of prolactinoma associated with craniopharyngioma. Article in Japanese. No Shinkei Geka. 1987;15(12):1313-1318.

17. Jiang ZW, Cheng BL. Pituitary adenoma associated with craniopharyngioma: a case report. Academic Journal of Second Military Medical University. 1987;8:67.

18. Cusimano MD, Kovacs K, Bilbao JM, et al. Suprasellar craniopharyngioma associated with hyperprolactinemia, pituitary lactotroph hyperplasia, and microprolactinoma. Case report. $J$ Neurosurg. 1988;69(4):620-623.

19. Yoshida A, Sen C, Asa SL, et al. Composite pituitary adenoma and craniopharyngioma?: an unusual sellar neoplasm with divergent differentiation. Am J Surg Pathol. 2008;32(11):1736-1741.

20. Karavitaki N, Scheithauer BW, Watt J, et al. Collision lesions of the sella: co-existence of craniopharyngioma with gonadotroph adenoma and of Rathke's cleft cyst with corticotroph adenoma. Pituitary. 2008;11(3):317-323.

21. Sargis RM, Wollmann RL, Pytel P. A 59 year-old man with sellar lesion. Brain Pathol. 2009;19(1):161-162.

22. Moshkin O, Scheithauer BW, Syro LV, et al. Collision tumors of the sella: craniopharyngioma and silent pituitary adenoma subtype 3: case report. Endocr Pathol. 2009;20(1):50-55.
23. Gokden M, Mrak RE. Pituitary adenoma with craniopharyngioma component. Hum Pathol. 2009;40(8):1189-1193.

24. Jin G, Hao S, Xie J, et al. Collision tumors of the sella: coexistence of pituitary adenoma and craniopharyngioma in the sellar region. World J Surg Oncol. 2013;11:178.

25. Finzi G, Cerati M, Marando A, et al. Mixed pituitary adenoma/ craniopharyngioma: clinical, morphological, immunohistochemical and ultrastructural study of a case, review of the literature, and pathogenetic and nosological considerations. Pituitary. 2014;17(1):53-59.

26. Miyazaki T, Kowari K, EdaH, etal. Ten-year follow-up of collision tumors composed of craniopharyngioma and pituitary adenoma: a case report and literature review. Case Rep Med. 2019;2019:8080163.

27. Snyder R, Fayed I, Dowlati E, et al. Pituitary adenoma and craniopharyngioma collision tumor: diagnostic, treatment considerations, and review of the literature. World Neurosurg. 2019;121:211-216.

28. Bteich F, El Khoury L, Nohra G, et al. Pituitary adenoma and papillary craniopharyngioma: a rare case of collision tumor and review of the literature. World Neurosurg. 2020;139:63-69.

29. El-Bilbeisi H, Ghannam M, Nimri CF, et al. Craniopharyngioma in a patient with acromegaly due to a pituitary macroadenoma. Ann Saudi Med. 2010;30(6):485-488.

30. Guaraldi F, Prencipe N, di Giacomo V, et al. Association of craniopharyngioma and pituitary adenoma. Endocrine. 2013;44(1):59-65.

31. Goschzik T, Gessi M, Dreschmann V, et al. Genomic alterations of adamantinomatous and papillary craniopharyngioma. J Neuropathol Exp Neurol. 2017;76(2):126-134.

32. Roque A, Odia Y. BRAF-V600E mutant papillary craniopharyngioma dramatically responds to combination BRAF and MEK inhibitors. CNS Oncol. 2017:6(2):95-99.

33. Rostami E, Witt Nyström $P$, Libard $S$, et al. Recurrent papillary craniopharyngioma with BRAFV600E mutation treated with neoadjuvant-targeted therapy. Acta Neurochir (Wien). 2017; 159(11):2217-2221.

34. Himes BT, Ruff MW, Van Gompel JJ, et al. Recurrent papillary craniopharyngioma with BRAF V600E mutation treated with dabrafenib: case report. J Neurosurg. 2018;130(4):1039-1408.

35. Alexandraki KI, Kaltsas GA, Karavitaki N, et al. The medical therapy of craniopharyngiomas: the way ahead. J Clin Endocrinol Metab. 2019;104(12):5751-5764.

36. Bernstein A, Mrowczynski OD, Greene A, et al. Dual BRAF/MEK therapy in BRAF V600E-mutated primary brain tumors: a case series showing dramatic clinical and radiographic responses and a reduction in cutaneous toxicity. J Neurosurg. 2019;133(6):1635-1978.

37. Rao M, Bhattacharjee M, Shepard S, et al. Newly diagnosed papillary craniopharyngioma with BRAF V600E mutation treated with single-agent selective BRAF inhibitor dabrafenib: a case report. Oncotarget. 2019;10(57):6038-6042.

\section{Disclosures}

The authors report no conflict of interest concerning the materials or methods used in this study or the findings specified in this paper.

\section{Author Contributions}

Conception and design: Schulder, Park, Golub. Acquisition of data: Schulder, Park, Li. Analysis and interpretation of data: Schulder, Park, Mishra, Golub, Li. Drafting the article: Park, Mishra, Golub. Critically revising the article: Schulder, Park, Mishra, Golub, Li. Reviewed submitted version of manuscript: Schulder, Park, Mishra, Li, Black. Approved the final version of the manuscript on behalf of all authors: Schulder. Administrative/technical/ material support: Schulder, Park, Mishra, Black.

\section{Correspondence}

Michael Schulder: North Shore University Hospital, Manhasset, NY. mschulder@northwell.edu. 